\title{
Genomic deletion and promoter methylation status of Hypermethylated in Cancer 1 (HIC1) in mantle cell lymphoma
}

\author{
Heike Stöcklein • Grit Hutter • Jörg Kalla • \\ Elena Hartmann • Yvonne Zimmermann • \\ Tiemo Katzenberger • Patrick Adam • Ellen Leich • \\ Sylvia Höller • Hans Konrad Müller-Hermelink • \\ Andreas Rosenwald • German Ott • Martin Dreyling
}

Received: 14 February 2008 / Accepted: 10 May 2008 / Published online: 5 July 2008

(C) Springer-Verlag 2008

\begin{abstract}
Mantle cell lymphomas (MCL), characterized by the $\mathrm{t}(11 ; 14)(\mathrm{q} 13 ; \mathrm{q} 32)$, frequently carry secondary genetic alterations such as deletions in chromosome $17 \mathrm{p}$ involving the TP53 locus. Given that the association between TP53deletions and concurrent mutations of the remaining allele is weak and based on our recent report that the Hypermethylated in Cancer 1 (HICl) gene, that is located telomeric to the TP53 gene, may be targeted by deletions in $17 \mathrm{p}$ in diffuse large B-cell lymphoma (DLBCL), we investigated whether $\mathrm{HICl}$ inactivations might also occur in MCL. Monoallelic deletions of the TP53 locus were detected in 18 out of 59 MCL (31\%), while overexpression of p53
\end{abstract}

Heike Stöcklein, Grit Hutter, and Jörg Kalla contributed equally to this work.

Andreas Rosenwald, German Ott, and Martin Dreyling are co-senior authors of this study.

H. Stöcklein · J. Kalla $\cdot$ E. Hartmann · T. Katzenberger •

P. Adam · E. Leich · S. Höller · H. K. Müller-Hermelink •

A. Rosenwald $\cdot$ G. Ott

Institute of Pathology, University of Würzburg,

Würzburg, Germany

H. Stöcklein

Dr Margarete Fischer-Bosch Institute of Clinical Pharmacology,

Stuttgart, Germany

G. Hutter $\cdot$ Y. Zimmermann $\cdot$ M. Dreyling

Department of Medicine III,

University Hospital Grosshadern/LMU, CCG Leukemia, GSF-National Research Center for Environment and Health, Munich, Germany

G. Ott $(\bowtie)$

Department of Clinical Pathology, Robert-Bosch-Krankenhaus, Auerbachstr. 110, 70376 Stuttgart, Germany

e-mail: german.ott@rbk.de protein occurred in only 8 out of 18 of these MCL (44\%). In TP53-deleted MCL, the $\mathrm{HICl}$ gene locus was co-deleted in 11 out of 18 cases $(61 \%)$. However, neither TP53 nor HICl deletions did affect survival of MCL patients. In most analyzed cases, no hypermethylation of the $\mathrm{HICl}$ exon $1 \mathrm{~A}$ promoter was observed (17 out of 20,85\%). However, in MCL cell lines without $\mathrm{HICl}$-hypermethylation, the mRNA expression levels of $\mathrm{HICl}$ were nevertheless significantly reduced, when compared to reactive lymph node specimens, pointing to the occurrence of mechanisms other than epigenetic or genetic events for the inactivation of $\mathrm{HICl}$ in this entity.

Keywords Mantle cell lymphoma $\cdot \operatorname{del}(17 \mathrm{p}) \cdot$ TP53 $\cdot$ HIC1

\section{Introduction}

Mantle cell lymphoma (MCL), an aggressive subtype of Bcell non-Hodgkin lymphomas (B-NHL), comprises 5-10\% of human B-cell lymphomas approximately [1]. The clinical course is heterogeneous, with survival times ranging from a few months to more than 10 years [2-4]. The hallmark genetic feature of this neoplasm is the translocation $\mathrm{t}(11 ; 14)(\mathrm{q} 13 ; \mathrm{q} 32)$ that juxtaposes the cyclin D1 gene and the enhancer region of the immunoglobulin heavy chain genes, leading to constitutive overexpression of cyclin D1 [5-8]. Although the deregulation of cyclin D1 is thought to be the primary genetic alteration in the pathogenesis of MCL, additional oncogenic events are required to promote tumor progression [9]. Various studies that applied genome-wide techniques to unravel secondary chromosomal aberrations in MCL, resulted in the characterization of frequently deleted regions and subsequently in the identification of particular tumor suppressor genes (e.g., 
$A T M, B I M, C D K N 2 A)$. However, in many deleted regions, candidate tumor suppressors have not been identified so far $[7,10-15]$.

One critical tumor suppressor gene that is frequently targeted by deletions in the short arm of chromosome 17 is the transcription factor TP53. In MCL, TP53 gene deletions are almost invariably associated with a loss of the whole arm of chromosome 17p [7, 10,12]. Whether, therefore, loss of the TP53 locus represents the most important biological consequence of $17 \mathrm{p}$ deletions in MCL, remains unknown. We recently reported that the tumor suppressor candidate Hypermethylated in Cancer 1 (HIC1), which is located in the chromosome band $17 \mathrm{p} 13.3$ telomeric to the TP53 locus, is frequently inactivated by concurrent deletion and promoter hypermethylation in diffuse large B-cell lymphoma (DLBCL) [16]. To investigate whether inactivation of $\mathrm{HICl}$ also occurs in MCL, we performed a detailed analysis of the chromosome $17 \mathrm{p}$ deletion status on the basis of conventional cytogenetic analysis, fluorescence in situ hybridization (FISH), polymerase chain reaction (PCR)-based loss of heterozygosity $(\mathrm{LOH})$ analysis, and quantitative real-time (RT-qPCR) approaches. Our results demonstrate that HICl, although frequently co-deleted with TP53 in $17 \mathrm{p} 13.3$, is - in contrast to DLBCL - infrequently hypermethylated in MCL suggesting that deletions of $17 \mathrm{p}$ might have different biological consequences in MCL and DLBCL.

\section{Material and methods}

Tumor specimens and cell lines

Fifty-nine MCL specimens, referred to the Institute of Pathology, University of Würzburg, were classified according to the criteria of the World Health Organization (WHO) classification system [17]. Cyclin D1 overexpression or the presence of the $\mathrm{t}(11 ; 14)(\mathrm{q} 13 ; \mathrm{q} 32)$ were identified in all cases by immunohistochemistry or FISH analysis, respectively. Genomic DNA was extracted from formalin-fixed and paraffin-embedded tissue ( 7 out of 59), from freshfrozen tissue (18 out of 59), and from leukemic blood specimens (34 out of 59) as previously described [16, 18].

Among these $59 \mathrm{MCL}$ patients, 47 were male and 12 female. The median age at diagnosis was 66 years (range 48 to 97 years), and median survival was 2.2 years. Of 59 MCL, 45 tumors were obtained at the time of primary diagnosis, while 14 lymphoma samples were relapsed MCL. Our study was approved by the local Ethics Committee of the University of Würzburg, Germany. The therapy was heterogeneous but, in most patients CHOPbased (without addition of Rituximab).

The human MCL cell lines used in this study were GRANTA-519, HBL2, MINO, REC1, and JVM2. All cell lines were obtained from the German Collection of Microorganisms and Cell Cultures (DSMZ, Braunschweig, Germany) and were maintained in Roswell Park Memorial Institute-1640 cell culture medium (PAA, Pasching, Austria) supplemented with $10 \%$ fetal calf serum (PAA, Pasching, Austria). DNA and RNA were extracted using the AllPrep DNA/RNA Mini Kit (Qiagen, Hilden, Germany) according the manufacturer's protocol.

\section{Chromosome banding analysis}

Chromosome spreads were prepared from lymphocyte short-term cultures in 46 of $59 \mathrm{MCL}$ cases according to standard protocols [19]. After Giemsa-trypsin banding, the karyotypes were established according to the International System for Human Cytogenetic Nomenclature (ISCN) [20]. Identical structural aberrations, or genetic gains, in two or more metaphases and identical genetic losses in at least three metaphases were defined as clonal.

\section{Immunohistochemistry}

Immunohistochemical staining for the p53 protein was assessed on freshly cut slides from formalin-fixed and paraffin-embedded tissues using the DO-7 antibody (1:50; DAKO, Glostrup, Denmark), as previously reported [21]. The staining for p53 was considered positive when $\geq 20 \%$ of tumor cells showed strong nuclear reactivity.

\section{Interphase fluorescence in situ hybridization}

Interphase FISH with TP53- and HIC1-locus-specific probes, using BAC clones RP11-199F11 and RP11-667K14, respectively, was performed according to previously published protocols [16]. The BAC clones were obtained from the libraries RPCIB753 and RPCIP704 of the RZPD German Resource Center for Genome Research (Berlin, Germany).

To determine the cutoff level for each probe, control studies with five reactive lymph node specimens were carried out. The cutoff ratios for RP11-199F11 and RP11-667K14 were $11.7 \%$ and $11.8 \%$, respectively. Signal visualization of at least 100 intact nuclei per case was accomplished on a Leica fluorescence microscope (Leica Microsystems, Bensheim, Germany). Illustrations were documented using the ISIS imaging system (MetaSystems, Altlussheim, Germany).

\section{Real-time quantitative PCR}

To detect genomic losses of the HICl and TP53 loci in the tumor specimens, RT-qPCR using genomic DNA was performed as previously described [16]. All measurements were done in triplicates. Presence or loss of the genomic HICl or TP53 region was defined relative to the $\beta-2$ - 
microglobulin $(B 2 M)$ locus $(15 \mathrm{q} 21)$ and calculated with the standard curve method using DNA prepared from peripheral blood mononuclear cells of healthy volunteers. The cutoff ratios for deletion were determined by analyzing DNA of five reactive lymph nodes. The cutoff ratios for $H I C 1 / B 2 M$ and $T P 53 / B 2 M$ were 0.74 and 0.76 , respectively.

HIC1 mRNA expression was determined by TaqMan qRT-PCR. Reverse transcription of $1 \mu \mathrm{g}$ total RNA was carried out using the High Capacity cDNA Reverse Transcription Kit (Applied Biosystems, Foster City, CA, USA). qRT-PCR was performed with the ABI PRISM 7700 Sequence Detection System (Applied Biosystems). All measurements were done in triplicates and calculated with the standard curve method using cDNA of reactive lymph node specimen and $\beta$-Actin as endogenous control. Primers for HICl amplification were 5'-CTGGATCCGCCGT CAGC-3' (sense) and 5'- TGTCCAGCATCGTCTGC-3' (antisense). To amplify $\beta$-Actin, the following oligonucleotides were used: 5'-GACGAGGGCGTGCTGGT GGG-3' (sense) and 5'-GATGCCTCTCTTGCTCTGGGC3' (antisense).

\section{$\mathrm{LOH}$ analysis}

Normal and tumor DNA were analyzed for loss of heterozygosity (LOH) of the TP53 (D17S1678) and HIC1 (D17S831) gene loci as previously reported [18].

\section{Methylation analysis of $\mathrm{HICl}$}

DNA was bisulphite-modified as previously described [18]. Methylation-specific PCR (MSP) was carried out according to published protocols [22]. Primers used to amplify the 5'untranslated region (exon 1A) of the $\mathrm{HICl}$ gene were also reported previously [16].

Statistical analysis

The Kaplan-Meier method was used to estimate overall survival of the patients. The statistical significance of associations between the TP53 or HICl status and survival was determined by using the log rank test. A $p$ value of $<0.05$ was considered statistically significant. For all analyses, the SPSS software V12.0 (SPSS, Chicago, IL, USA) was used.

\section{Results}

Deletions of the TP53 gene locus are not strictly associated with altered $\mathrm{p} 53$ protein expression

To define the deletion status of TP53 in the chromosome band $17 \mathrm{p} 13.1$, fluorescence in situ hybridization (FISH) with the TP53-locus-specific probe RP11-199F11 was performed in 51 out of 59 MCL cases. In addition, tumor and normal DNA of 24 out of 59 MCL could be analyzed for loss of heterozygosity (LOH) of TP53 using the microsatellite marker D17S1678. A monoallelic deletion of the TP53 gene was observed in 18 out of 59 MCL (31\%) (Table 1).

In conventional cytogenetic analyses of 46 out of 59 MCL, a deletion in the short arm of chromosome 17 [del (17p)] corresponded with loss of the TP53 gene in 6 out of 18 samples, while in 8 out of 18 tumors, the monoallelic TP53-deletion, as detected by FISH and/or LOH, was not visible by chromosome banding. In four cases that harbored a deletion of the TP53-locus by FISH, no banding analyses were available (Table 1). Interestingly, conventional cytogenetic analysis revealed a del(17p) in two MCL, without affecting the TP53 locus as shown by FISH and LOH (Table 1).

To check for possible inactivating mutations of the second, non-deleted TP53 allele, we performed immunohistochemical staining of the p53 protein in 51 of 59 cases. An overexpression of the p53 protein was detected in 18 out of 51 MCL. Whereas eight of these cases harbored TP53 gene deletions, in the remaining ten MCL samples, accumulation of p53 protein occurred without corresponding deletion of the TP53 locus. Vice versa, no p53 overexpression was observed in 33 of 51 MCL. Of those, $25 \mathrm{MCL}$ did not harbor a deletion of the TP53 gene, while in 8 out of 33 tumors, a monoallelic TP53-deletion was detected (Table 1). Focusing on the eight MCL harboring a TP53 deletion without detectable p53 overexpression, three of these cases carried a $\operatorname{del}(17 \mathrm{p})$ by conventional cytogenetic analysis, while in three additional tumors, a del(17p) was not visible by chromosome banding. In the remaining two MCL, no chromosome banding data was available, and the TP53 deletion was defined only on the basis of FISH and LOH analyses (Table 1).

In summary, deletion of the TP53 locus in concert with overexpression of $\mathrm{p} 53$ protein suggesting $\mathrm{p} 53$ inactivation was evident in 8 of $59 \mathrm{MCL}$ (14\%). Of note, in 3 of $8 \mathrm{MCL}$ a del(17p), as indicated by conventional cytogenetic analysis, was not associated with overexpression of p53-protein. Moreover, in 2/59 MCL samples a del(17p) occurred without affecting the TP53-locus, pointing to the existence of another tumor suppressor gene in chromosome $17 \mathrm{p}$.

Deletion of Hypermethylated in Cancer 1 (HICl) gene in the chromosome band $17 \mathrm{p} 13.3$ occurs in addition to the loss of TP53 gene locus in MCL

Because we had observed an inactivation of $\mathrm{HICl}$ by monoallelic deletion and concurrent promoter hypermethylation of the remaining allele in diffuse large B-cell 


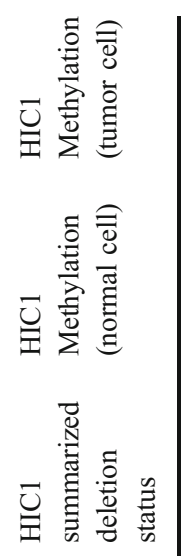

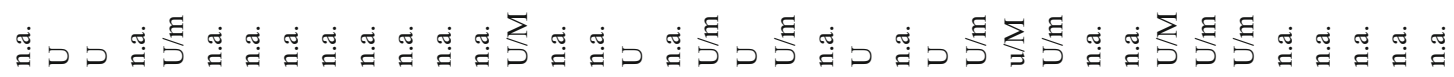

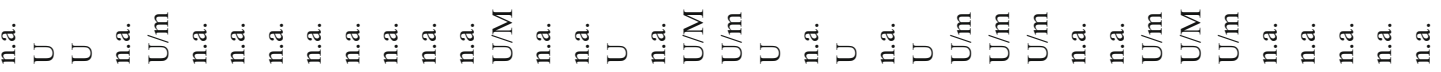

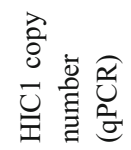

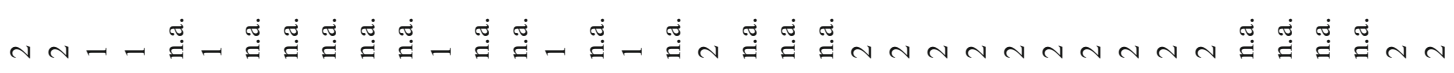

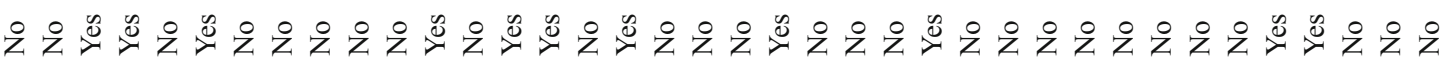

\section{층 \\ 总总 愛}

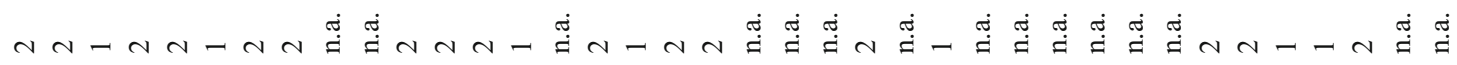

宓

总部

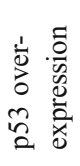

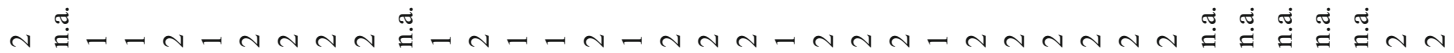

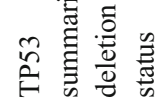

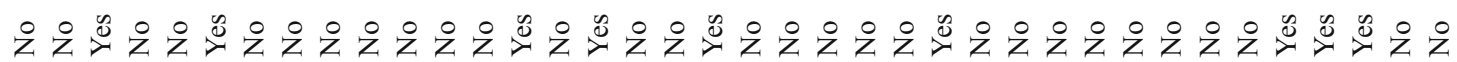

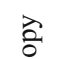

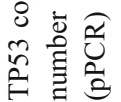

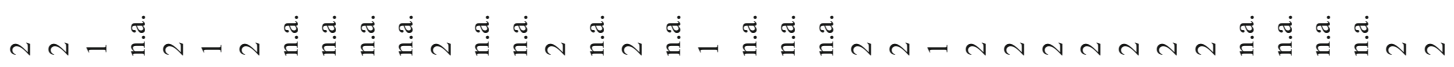

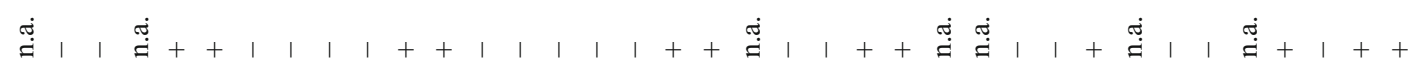
亏े

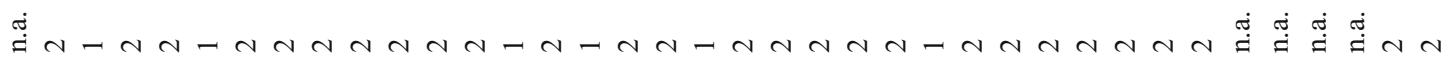

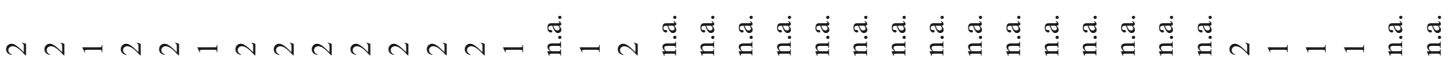
N 促 


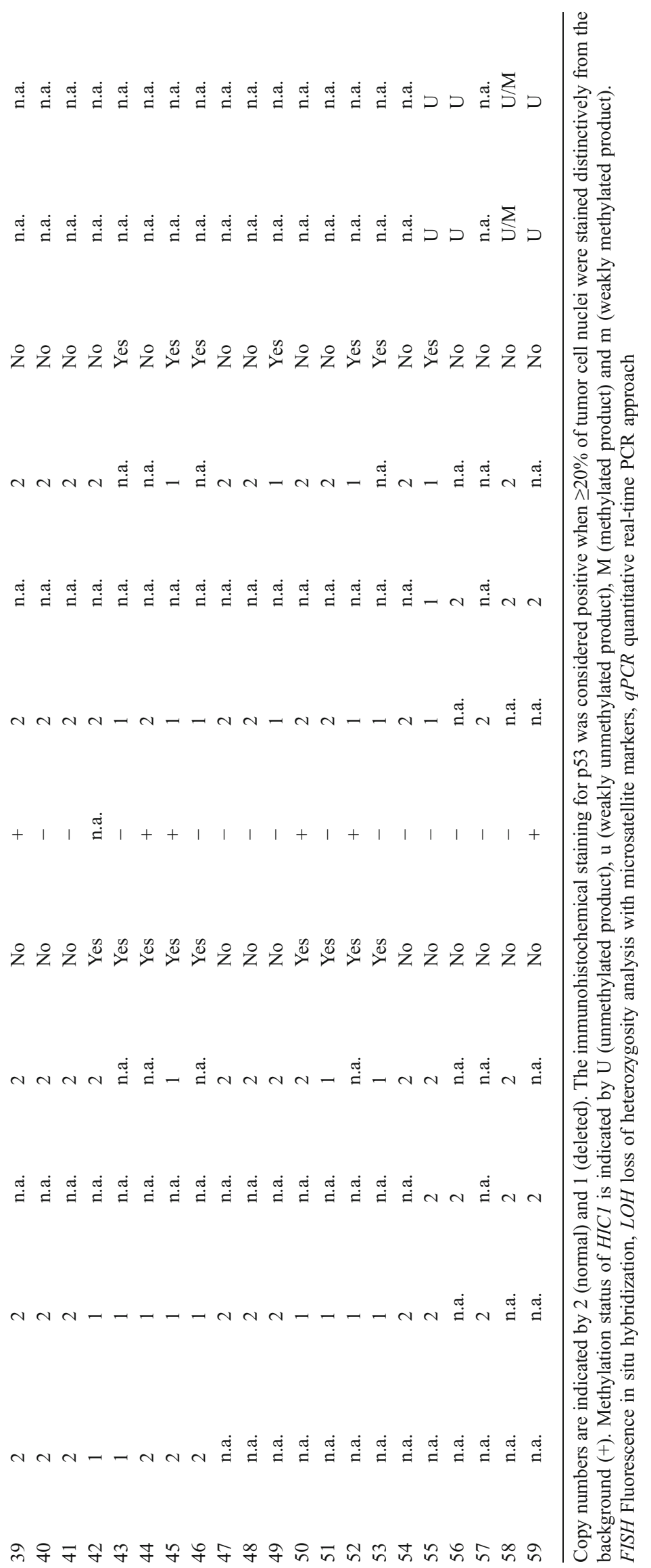


lymphomas (DLBCL) [16], we examined, whether the deletion of $\mathrm{HIC1}$, located in the chromosome band $17 \mathrm{p} 13.3$ telomeric to TP53, might also be associated with the pathogenesis of MCL.

The deletion status of $\mathrm{HICl}$ was examined in $59 \mathrm{MCL}$, using FISH with the HICl locus-specific probe RP11$667 \mathrm{~K} 14$ (in 32 out of 59 fresh-frozen and leukemic blood samples) or $\mathrm{LOH}$ analysis with the microsatellite marker D17S831 (on DNA from 10/59 MCL samples extracted from leukemic blood) or by using both methods when appropriate material was available (in 17 out of $59 \mathrm{MCL}$ ). A monoallelic deletion of RP11-667K14 by FISH and/or loss of heterozygosity of D17S831 by LOH analysis was observed in 18 out of 59 cases (31\%) (Table 1). Deletion of both the HICl and TP53 loci simultaneously occurred in only 11 of these MCL. By conventional cytogenetic analysis, a del(17p) was detected in 4 out of $11 \mathrm{MCL}$ samples, indicating complete loss of chromosome $17 \mathrm{p}$ in these cases (Table 1, Fig. 1a-c).

In 7 out of 18 HICl-deleted MCL, no loss of the TP53 gene was observed. Two of these cases were shown to harbor a del( $17 \mathrm{p})$ by cytogenetic analysis without concomitant loss of the TP53 locus, indicating a del(17p), with a breakpoint telomeric to the chromosome band 17p13.1, harboring the TP53 locus (Table 1, Fig. 1a,f-g).
In 41 out of $59 \mathrm{MCL}$, no deletion of $\mathrm{HICl}$ was detected, but seven of these cases carried a monoallelic TP53 deletion. Two of these MCL cases harbored a del(17p) by conventional cytogenetics, which suggests a deletion of chromosome $17 \mathrm{p}$, excluding the telomeric part of the region containing the HICl gene (Table 1, Fig. 1a,d-e).

To validate the deletion pattern of $H I C l$ and TP53 with an alternative technique, we used quantitative PCR (qPCR) in 33 MCL to determine the HICl and TP53 deletion status in correlation to the reference gene beta-2-microglobulin $(B 2 M)$. By this approach, 22 of 33 samples were shown to harbor a normal TP53 and HICl status, as indicated by $H I C 1 / B 2 M$ and TP53/B2M ratios ranging between 0.95 and 1.06 , comparable to the results of FISH and LOH experiments (Table 1, Fig. 2). Monoallelic deletion of the TP53 gene without loss of the $\mathrm{HICl}$ locus was observed in 3 out of 33 MCL (nos. 19, 25 and 51) by qPCR (Table 1, Fig. 2). In 5 out of 33 tumors (nos. 12, 15, 17, 49 and 55), which exhibited one FISH signal with the $\mathrm{HICl}$-specific probe, $\mathrm{HICl}$ deletion was observed by qPCR, as indicated by HICl/ $B 2 M$ ratios between 0.19 and 0.31 , while a normal status was detected for the TP53 gene (Table 1, Fig. 2). A concurrent deletion of both the HIC1 and TP53 gene loci was found in 3 out of $33 \mathrm{MCL}$ (nos. 3, 6, and 45), confirming the results of FISH and LOH experiments (Table 1, Fig. 2).

\section{A}

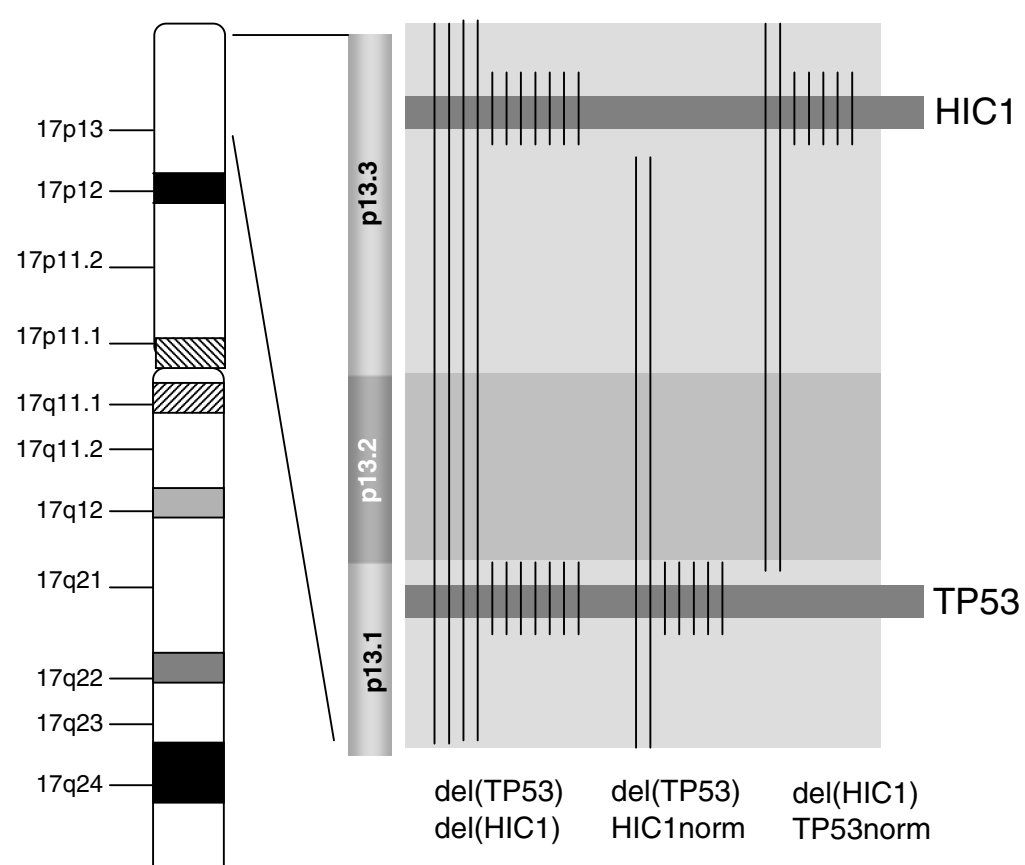

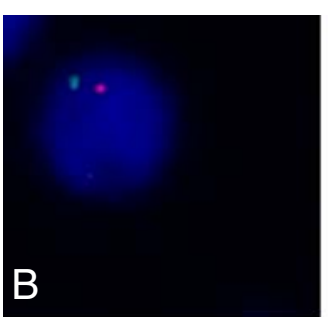
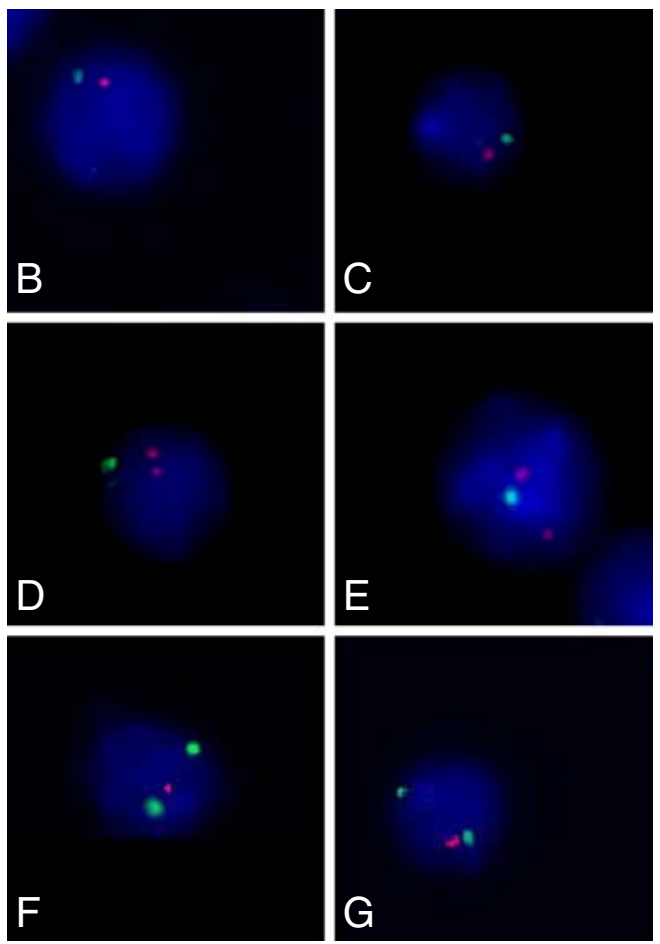

Fig. 1 Chromosome $17 \mathrm{p}$ deletions in MCL. Whole arm deletion of chromosome 17p, including TP53 and HIC1, in 11/59 MCL (a), as indicated by fluorescence in situ hybridization using the TP53-specific probe RP11-199F11 (green) and the HIC1-specific probe RP11$667 \mathrm{~K} 14$ (red) (b-c). Partial deletion of chromosome band 17p13.1 to 17 p13.3 including only the TP53-locus in 7 out of 59 MCL (a), as seen by loss of one green signal (TP53) in contrast to two HIC1signals (red) (d-e). Deletion of chromosomal band 17p13.3, including HICl without loss of TP53 in 7/59 MCL (a), as indicated by one HIC1-signal (red) instead of two TP53-signals (green; f-g) 


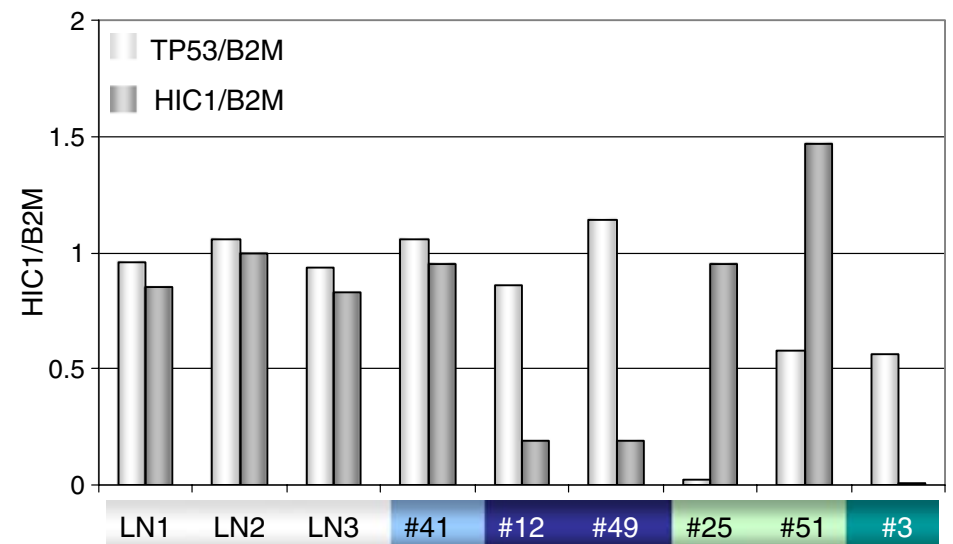

TP53 norm / HIC1 norm

TP53 norm / HIC1 del

TP53 del / HIC1 norm

TP53 del / HIC1 del

Fig. 2 Genomic deletions of the HIC1 and TP53 loci detected by quantitative real-time PCR. Three reactive lymph node samples show $H I C 1 / B 2 M$ and $T P 53 / B 2 M$ ratios close to 1 , indicating wild type configuration of both loci (LN1-LN3, grey), as also presented for MCL no. 41 (light blue). Two MCL (nos. 12, 49) show a HIC1/B2M ratio below the cutoff level indicating a deletion of the HICl locus, while the TP53/B2M ratio indicates wild-type configuration of the TP53 locus (dark blue). Two MCL (nos. 25, 51) show evidence of a TP53 deletion in the presence of two copies of HICl (light green). One MCL (no. 3) harbors a co-deletion of the HICl and TP53 loci (dark green)

from granulocytes of the same patient sample (Fig. 3a, Table 1). In only one of these cases, HICl methylation was associated with a concomitant deletion of the HICl locus (Table 1). In 14 out of 20 cases ( $70 \%$ ), no alteration of exon 1A promoter methylation was observed in the lymphocyte DNA when compared to DNA from nonmalignant granulocytes. The majority of these cases showed unmethylated DNA in both normal and tumor cells (in 8 out of 14 cases, Fig. 3b, Table 1), while weakly methylated DNA of both tumor and normal cells was detected in 6 out of $14 \mathrm{MCL}$ (Fig. 3c, Table 1). In 3 out of 20 cases (15\%), HICl methylation was observed in DNA of granulocytes, while in lymphocytes from the same patient, the $\mathrm{HICl}$-promoter appeared to be less methylated (Fig. 3d, Table 1).

To ensure that the epigenetic HICl profile of MCL cells in leukemic peripheral blood reflects that obtained from MCL cells in lymph nodes, we analyzed DNA extracted from lymph node specimens in addition to the leukemic peripheral blood in 3 out of 20 cases. No differences in the HICl methylation status were observed when comparing methylation in the tumor DNA, in contrast to DNA obtained

C

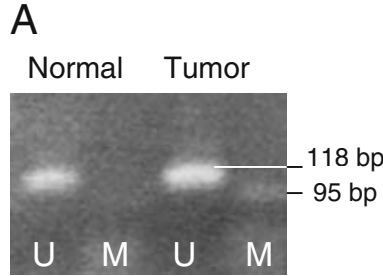

MCL \#21
B

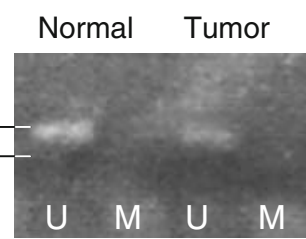

MCL \#55
Normal Tumor Normal Tumor

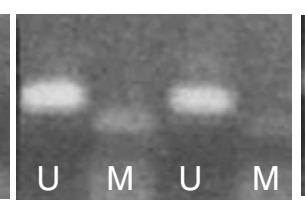

MCL \#33

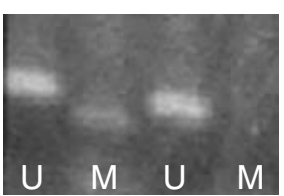

MCL \#20
Fig. 3 Methylation-specific PCR of the 5'-UTR of $\mathrm{HICl}$ in granulocytes (normal) and lymphocytes (tumor) of MCL patients. Samples containing methylated DNA produced PCR amplicons with the $\mathrm{M}$ (methylated) primer set, while samples without methylation yielded PCR products when the U (unmethylated) primer set was applied. Promoter methylation of $\mathrm{HICl}$ in tumor cells, while normal cells showed unmethylated HIC1-sequence in MCL no. 21 (a). Neither normal, nor tumor cells harbored methylated DNA product in MCL no. 55 (b). Slightly methylated DNA in normal and tumor cells in MCL no. 33 (c). Methylation of the HIC1-promoter in normal, but not in tumor cells in MCL no. 20 (d) 
DNA extracted from lymph node and peripheral blood in these MCL (data not shown).

Reduced HIC1 mRNA levels in MCL cell lines are not associated with promoter hypermethylation

To investigate the possible role of HIC1 in MCL pathogenesis in more detail, we studied the five MCL cell lines GRANTA-519, HBL2, MINO, REC1, JVM2, first, to determine the methylation status of $\mathrm{HICl}$ and, second, to assess HIC1 gene expression level. It has to be emphasized that none of the cell lines harbor homozygous deletion of chromosome $17 \mathrm{p}$, as assessed by $500 \mathrm{~K}$ SNP array analysis (E. Hartmann, unpublished data). While GRANTA-519, HBL2, and MINO presented with monoallelic deletions in the short arm of chromosome 17, including TP53 and HIC1 gene locus, REC1 and JVM2 showed a normal diploid status of $17 \mathrm{p}$. None of the cell lines presented with an aberrant methylation of the $\mathrm{HICl}$ exon 1A promoter, comparable to those results obtained from reactive lymph node specimens and in the majority of the primary MCL tumors (Fig. 4a). However, expression levels of HICl mRNA were significantly reduced in MCL cell lines, in contrast to the normal lymphoid tissue samples ( $p=0.001$, Fig. $4 \mathrm{~b})$.

Monoallelic deletion of the HICl locus is not associated with survival of MCL patients

HIC1 and TP53 inactivations have recently been reported to be negative prognostic markers in diffuse large B-cell lymphoma. To analyze the clinical course of MCL patients according to their HIC1 and TP53 status, we compared the patients' survival data of 34 out of 59 cases with a deletion of either HICl or TP53, as well as of MCL patients with overexpression of p53 protein. Given the caveat of a small patient series, neither TP53 deletions nor deletions of the HIC1 gene locus were associated with inferior survival of MCL patients (Fig. 5a,c). Overexpression of p53 protein, however, clearly predicted for inferior outcome compared to tumors from MCL patients lacking expression of the protein $(p \leq 0.0001$, Fig. $5 b)$.

\section{Discussion}

MCL is a well-defined subtype of B-cell non-Hodgkin lymphoma, characterized by the translocation $\mathrm{t}(11 ; 14)(\mathrm{q} 13$; q32), which is present in virtually all cases. In addition to this translocation, MCL tumor cells harbor various secondary chromosomal alterations [27]. One critical regulator of cell survival is the tumor suppressor gene TP53, located in chromosome band $17 \mathrm{p} 13.1$, a genomic region frequently deleted in MCL [7]. On the basis of the two-hit hypothesis, the inactivation of a tumor suppressor gene, e.g., by concurrent deletion and mutation/hypermethylation of the second allele, is considered a prerequisite for tumor progression [28, 29]. The association of TP53 gene deletions and mutation of the remaining non-deleted TP53-allele, however, has been reported to be only weak in MCL [30, 31]. This is also confirmed in our series, in which 18 out of 59 MCL (31\%) harbored a monoallelic TP53 deletion, while only eight of these cases (44\%)
Fig. 4 HICl promoter methylation and mRNA expression in MCL cell lines. None of the analyzed MCL cell lines showed aberrant methylation pattern of the $\mathrm{HICl}$ exon $1 \mathrm{~A}$ promoter, with amplification of the $U$ (unmethylated) primer set, in line with the unmethylated $\mathrm{HICl}$ promoter in reactive lymph node specimens. As a control RAJI cell line was used, yielding PCR product when the $\mathrm{M}$ (methylated) primer set was applied (a). In contrast to reactive lymphnode specimens, the $\mathrm{HICl}$ mRNA expression was significantly reduced in all MCL cell lines $(\mathbf{b})$
A
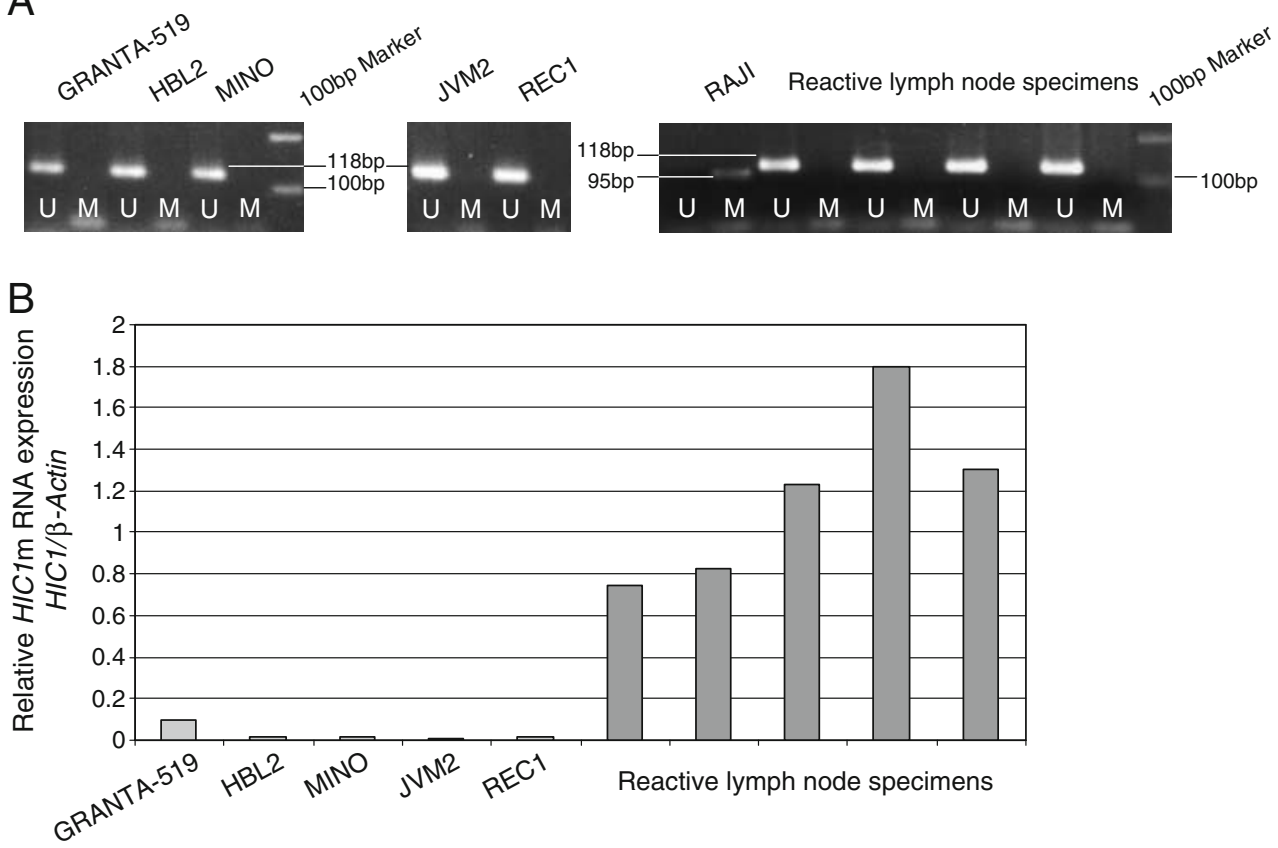


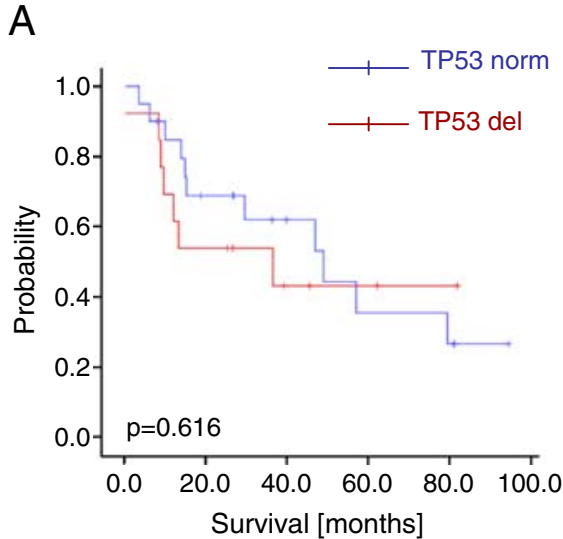

Fig. 5 Survival analysis of MCL patients according to the TP53 and HICl status. Kaplan-Meier survival curves for patients with monoallelic deletion of TP53 (a), overexpression of p53 protein (b) and for

showed an overexpression of p53 protein suggesting the inactivation of the remaining TP53 allele by gene mutation. The finding that 10 out of $18 \mathrm{MCL}$ showed monoallelic TP53 deletions without concomitant overexpression of p53 protein might be pointing to the existence of another candidate tumor suppressor gene on chromosome $17 \mathrm{p}$ in MCL. Because no mutational analysis of the TP53 gene had been performed in this study, we cannot entirely exclude the occurrence of complete TP53 inactivation in these cases by immunohistochemical analysis of p53 protein expression, given its false-negative results, especially in the context of non-sense and truncating mutations of the TP53 gene [32, 33]. However, we consider it unlikely that this scenario accounts for the lack of p53 protein expression in the majority of cases, as most of the TP53 mutations occurring in MCL are missense mutations which do not result in truncated $\mathrm{p} 53$ protein $[34,35]$. In addition, it has been reported that discordances between the results of p53 immunohistochemistry and mutational analysis of the TP53 gene can also be due to alternative mechanisms of p53 stabilization, leading to overexpression of p53 protein without concomitant TP53 gene mutation. In contrast, none of the previously published MCL cases lacking p53-overexpression showed mutation of the TP53 gene [34-36].

In addition to ten MCL that harbored monoallelic TP53 deletions without concurrent overexpression of $\mathrm{p} 53$ protein in our series, a deletion of the short arm of chromosome 17 was detected in two MCL, without affecting the TP53 gene locus. This finding points to the loss of genomic material telomeric to the TP53 locus, possibly inactivating other tumor suppressor genes, which is consistent with the previous finding of novel recurrently deleted regions in 17p13.3, as reported for MCL [37], but also for DLBCL [16] and various leukemia subtypes [38]. These findings provide support for the hypothesis that genomic deletions involving the chromosomal band $17 \mathrm{p} 13$ may not always affect TP53 itself and raises the question whether other
C

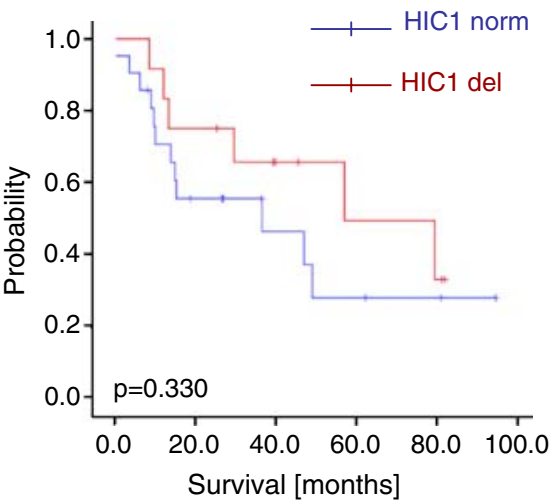

MCL patients with monoallelic deletion of HICl (c). Norm Normal, del deleted, p53+ overexpression of p53-protein, p53- no overexpression of p53-protein

tumor suppressor genes might be targeted by deletions in this genomic region. The chromosomal band $17 \mathrm{p} 13.3$ harbors several candidate genes, such as LOST1, DPH2L1, OVCA2, MNT/ROX, or HICl, which had been described to be altered in various cancer types [39-42]. Because the tumor suppressor candidate $\mathrm{HICl}$ had previously been reported to be frequently inactivated in DLBCL [16], as well as in acute lymphocytic leukemia, in chronic myelogenous leukemia [43], and in acute myeloid leukemia [44], we focused our investigation in MCL on this candidate.

Monoallelic deletion of the $\mathrm{HICl}$ gene was observed in 18 out of $59 \mathrm{MCL}$ analyzed. Interestingly, HIC1 deletions were detected in 7 out of these 18 cases that did not show evidence of a concurrent genomic loss of the TP53 locus. Two of these cases harbored a del(17p), as indicated by cytogenetic analyses, suggesting a partial deletion of chromosome $17 \mathrm{p}$ telomeric to TP53 gene, as had been recently described in DLBCL [16], as well as in myeloid and lymphoid leukemia [38].

Because $\mathrm{HICl}$ has been reported to be frequently inactivated by promoter hypermethylation, but not by mutation [23, 42], we focused our investigation on the methylation status. However, methylation of the $\mathrm{HICl}$ exon $1 \mathrm{~A}$ promoter was only rarely encountered in MCL, in contrast to our previous findings in DLBCL [16]. The lack of $\mathrm{HICl}$ hypermethylation in the MCL cell lines GRANTA519, HBL2, MINO, JVM2, and REC1 further supports our findings that aberrant promoter methylation of $\mathrm{HICl}$ is an infrequent event in MCL. Nevertheless, the mRNA expression levels of $\mathrm{HICl}$ were significantly reduced in the MCL cell lines studied when compared to those observed in reactive lymphoid tissues, indicating that the inactivation of HICl is not necessarily correlated with epigenetic or genetic events affecting the gene locus, but may be due to alternative mechanisms of $\mathrm{HICl}$ inactivation. Of note, the reduction of $\mathrm{HICl}$ mRNA expression, independent of $\mathrm{HICl}$ promoter hypermethylation, has been recently reported in 
hematological malignancies [45]. In keeping with previous findings about a possible role of $\mathrm{HICl}$ in the differentiation of solid tumors, Britschgi et al. reported a decrease of $\mathrm{HICl}$ expression level in primary human acute myeloid leukaemia (AML) when compared with terminally differentiated granulocytes. Although the mechanism by which $\mathrm{HICl}$ is inactivated may not be related to genetic or epigenetic alterations, Britschgi and colleagues suggested that the repression of retinoic acid receptor signaling in leukaemia possibly causes downregulation of HIC1 mRNA expression [45].

Although not epigenetically inactivated, the MCL subset studied here presented with a high proportion of monoallelic deletions of the $\mathrm{HICl}$ gene locus. The heterozygous loss of $\mathrm{HICl}$ function in mice has been reported to result in earlier tumor formation and increased aggressiveness in TP53-altered mice [46], and a potential synergistic effect of TP53 and HICl inactivation with respect to clinical outcome could be demonstrated in DLBCL patients [16]. Although limited by the small number of cases and the heterogenous treatment of MCL patients, neither the deletion of HICl nor the deletion of TP53 was associated with inferior overall survival. These results are in line with previous reports described for loss of TP53 [31] as well as for $17 \mathrm{p}$ deletions in MCL in general $[10,12,15]$. In contrast, deletion of chromosome $17 \mathrm{p}$ has also been reported to be of prognostic value in B-NHL [47] and specifically in MCL [11]. Because deletions of the TP53 or the HIC1 gene locus alone were not associated with the clinical outcome of MCL patients in our study, we cannot entirely exclude the presence of other tumor-relevant candidate genes in chromosome 17p, beyond TP53 and HICl.

Interestingly, overexpression of p53 by immunohistochemistry, possibly indicating an underlying TP53 gene mutation, was associated with significantly shorter overall survival of MCL patients in our series in accordance with reports about TP53 mutations in MCL [34, 35]. The impaired survival of MCL patients with tumors showing overexpression of $\mathrm{p} 53$ protein may therefore be explained by the dominant-negative effect of TP53-mutations that may drive the remaining wild-type p53 into the mutant conformation resulting in a complete TP53 inactivation [48].

In conclusion, our study provides further evidence that deletions in chromosome $17 \mathrm{p}$ are only weakly correlated with overexpression of $\mathrm{p} 53$ protein, indicating that the TP53 gene may not be the only target of this genomic alteration.

Although we demonstrate that in a subset of MCL, chromosome $17 \mathrm{p}$ deletions affect the genomic region around the HICl locus, the inactivation of $\mathrm{HICl}$ by promoter methylation of exon $1 \mathrm{~A}$ was only infrequently observed in MCL. However, in MCL cell lines without hypermethylation of the $\mathrm{HICl}$ promoter, the mRNA expression levels were significantly reduced, indicating alternative mechanisms for the inactivation of $\mathrm{HICl}$ in this tumor. Because reexpression of $\mathrm{HICl}$ was shown to be feasible in AML with downregulated HICl mRNA [45], it will be of interest to study a possible benefit of MCL patients restoring $\mathrm{HICl}$ function.

Acknowledgments We thank Heike Brückner, Irina Eichelbrönner, Doris Hetzer, and Petra Stempfle for their excellent technical assistance. A.R., E.H., and E.L. are supported by the Interdisciplinary Center for Clinical Research (IZKF), University of Würzburg. H.S. and G.O. are supported by the Robert-Bosch-Stiftung. This work was supported by the European Mantle Cell Lymphoma Network.

\section{References}

1. (1997) A clinical evaluation of the International Lymphoma Study Group classification of non-Hodgkin's lymphoma. The NonHodgkin's Lymphoma Classification Project. Blood 89:3909-3918

2. Argatoff LH, Connors JM, Klasa RJ et al (1997) Mantle cell lymphoma: a clinicopathologic study of 80 cases. Blood 89:20672078

3. Bosch F, Lopez-Guillermo A, Campo E et al (1998) Mantle cell lymphoma: presenting features, response to therapy, and prognostic factors. Cancer 82:567-75

4. Rosenwald A, Wright G, Wiestner A et al (2003) The proliferation gene expression signature is a quantitative integrator of oncogenic events that predicts survival in mantle cell lymphoma. Cancer Cell $3: 185-197$

5. Raffeld M, Jaffe ES (1991) bcl-1, t(11;14), and mantle cellderived lymphomas. Blood 78:259-263

6. Williams ME, Westermann CD, Swerdlow SH (1990) Genotypic characterization of centrocytic lymphoma: frequent rearrangement of the chromosome 11 bcl-1 locus. Blood 76:1387-1391

7. Jares P, Colomer D, Campo E (2007) Genetic and molecular pathogenesis of mantle cell lymphoma: perspectives for new targeted therapeutics. Nat Rev Cancer 7:750-762

8. Bosch F, Jares P, Campo E et al (1994) PRAD-1/cyclin D1 gene overexpression in chronic lymphoproliferative disorders: a highly specific marker of mantle cell lymphoma. Blood 84:2726-2732

9. Bodrug SE, Warner BJ, Bath ML et al (1994) Cyclin D1 transgene impedes lymphocyte maturation and collaborates in lymphomagenesis with the myc gene. Embo J 13:2124-2130

10. Bea S, Ribas M, Hernandez JM et al (1999) Increased number of chromosomal imbalances and high-level DNA amplifications in mantle cell lymphoma are associated with blastoid variants. Blood 93:4365-4374

11. Allen JE, Hough RE, Goepel JR et al (2002) Identification of novel regions of amplification and deletion within mantle cell lymphoma DNA by comparative genomic hybridization. Br J Haematol 116:291-298

12. Kohlhammer H, Schwaenen C, Wessendorf S et al (2004) Genomic DNA-chip hybridization in $\mathrm{t}(11 ; 14)$-positive mantle cell lymphomas shows a high frequency of aberrations and allows a refined characterization of consensus regions. Blood 104:795-801

13. Monni O, Oinonen R, Elonen E et al (1998) Gain of 3q and deletion of $11 \mathrm{q} 22$ are frequent aberrations in mantle cell lymphoma. Genes Chromosomes Cancer 21:298-307

14. Schraders M, Pfundt R, Straatman HM et al (2005) Novel chromosomal imbalances in mantle cell lymphoma detected by 
genome-wide array-based comparative genomic hybridization. Blood 105:1686-1693

15. Salaverria I, Zettl A, Bea S et al (2007) Specific secondary genetic alterations in mantle cell lymphoma provide prognostic information independent of the gene expression-based proliferation signature. J Clin Oncol 25:1216-1222

16. Stöcklein H, Smardova J, Macak J et al (2008) Detailed mapping of chromosome $17 \mathrm{p}$ deletions reveals $\mathrm{HICl}$ as a novel tumor suppressor gene candidate telomeric to TP53 in diffuse large Bcell lymphoma. Oncogene 27(18):2613-2625

17. Jaffe E, Harris N, Stein H et al (2001) World Health Organization classification of tumours: pathology and genetics of tumours of haematopoietic and lymphoid tissues.

18. Hutter G, Scheubner M, Zimmermann Y et al (2006) Differential effect of epigenetic alterations and genomic deletions of CDK inhibitors [p16(INK4a), p15(INK4b), p14(ARF)] in mantle cell lymphoma. Genes Chromosomes Cancer 45:203-210

19. Lichter P, Bentz M, Joos S (1995) Detection of chromosomal aberrations by means of molecular cytogenetics: painting of chromosomes and chromosomal subregions and comparative genomic hybridization. Methods Enzymol 254:334-359

20. Shaffer LG, Tommerup N (2005) An international system for human cytogenetic nomenclature. S. Karger AG, Memphis, TN

21. Rudiger T, Ott G, Ott MM et al (1998) Differential diagnosis between classic Hodgkin's lymphoma, T-cell-rich B-cell lymphoma, and paragranuloma by paraffin immunohistochemistry. Am J Surg Pathol 22:1184-1191

22. Herman JG, Graff JR, Myohanen S et al (1996) Methylationspecific PCR: a novel PCR assay for methylation status of $\mathrm{CpG}$ islands. Proc Natl Acad Sci U S A 93:9821-9826

23. Chen WY, Zeng X, Carter MG et al (2003) Heterozygous disruption of Hic1 predisposes mice to a gender-dependent spectrum of malignant tumors. Nat Genet 33:197-202

24. Dong SM, Kim HS, Rha SH et al (2001) Promoter hypermethylation of multiple genes in carcinoma of the uterine cervix. Clin Cancer Res 7:1982-1986

25. Waha A, Koch A, Hartmann W et al (2004) Analysis of HIC-1 methylation and transcription in human ependymomas. Int $\mathrm{J}$ Cancer 110:542-549

26. Ferrer A, Salaverria I, Bosch F et al (2007) Leukemic involvement is a common feature in mantle cell lymphoma. Cancer 109:2473-2480

27. Fernandez V, Hartmann E, Ott G et al (2005) Pathogenesis of mantlecell lymphoma: all oncogenic roads lead to dysregulation of cell cycle and DNA damage response pathways. J Clin Oncol 23:6364-6369

28. Knudson AG Jr (1971) Mutation and cancer: statistical study of retinoblastoma. Proc Natl Acad Sci U S A 68:820-823

29. Herman JG, Baylin SB (2003) Gene silencing in cancer in association with promoter hypermethylation. N Engl J Med 349:2042-2054

30. Solenthaler M, Matutes E, Brito-Babapulle V et al (2002) p53 and $\mathrm{mdm} 2$ in mantle cell lymphoma in leukemic phase. Haematologica $87: 1141-1150$

31. Greiner TC, Dasgupta C, Ho VV et al (2006) Mutation and genomic deletion status of ataxia telangiectasia mutated (ATM) and $\mathrm{p} 53$ confer specific gene expression profiles in mantle cell lymphoma. Proc Natl Acad Sci U S A 103:2352-2357
32. Hashimoto T, Tokuchi Y, Hayashi M et al (1999) p53 null mutations undetected by immunohistochemical staining predict a poor outcome with early-stage non-small cell lung carcinomas. Cancer Res 59:5572-5577

33. Wynford-Thomas D (1992) P53 in tumour pathology: can we trust immunocytochemistry? J Pathol 166:329-330

34. Greiner TC, Moynihan MJ, Chan WC et al (1996) p53 mutations in mantle cell lymphoma are associated with variant cytology and predict a poor prognosis. Blood 87:4302-4310

35. Hernandez L, Fest T, Cazorla M et al (1996) p53 gene mutations and protein overexpression are associated with aggressive variants of mantle cell lymphomas. Blood 87:3351-3359

36. Louie DC, Offit K, Jaslow R et al (1995) p53 overexpression as a marker of poor prognosis in mantle cell lymphomas with $\mathrm{t}(11 ; 14)$ (q13;q32). Blood 86:2892-2899

37. Tagawa H, Karnan S, Suzuki R et al (2005) Genome-wide arraybased CGH for mantle cell lymphoma: identification of homozygous deletions of the proapoptotic gene BIM. Oncogene 24:1348-1358

38. Sankar M, Tanaka K, Kumaravel TS et al (1998) Identification of a commonly deleted region at $17 \mathrm{p} 13.3$ in leukemia and lymphoma associated with $17 \mathrm{p}$ abnormality. Leukemia 12:510-516

39. Cvekl A Jr, Zavadil J, Birshtein BK et al (2004) Analysis of transcripts from $17 \mathrm{p} 13.3$ in medulloblastoma suggests ROX/MNT as a potential tumour suppressor gene. Eur J Cancer 40:25252532

40. Konishi H, Sugiyama M, Mizuno K et al (2003) Detailed characterization of a homozygously deleted region corresponding to a candidate tumor suppressor locus at distal $17 \mathrm{p} 13.3$ in human lung cancer. Oncogene 22:1892-1905

41. Schultz DC, Vanderveer L, Berman DB et al (1996) Identification of two candidate tumor suppressor genes on chromosome 17p13.3. Cancer Res 56:1997-2002

42. Wales MM, Biel MA, el Deiry W et al (1995) p53 activates expression of HIC-1, a new candidate tumour suppressor gene on 17p13.3. Nat Med 1:570-577

43. Issa JP, Zehnbauer BA, Kaufmann SH et al (1997) HIC1 hypermethylation is a late event in hematopoietic neoplasms. Cancer Res 57:1678-1681

44. Melki JR, Vincent PC, Clark SJ (1999) Concurrent DNA hypermethylation of multiple genes in acute myeloid leukemia. Cancer Res 59:3730-3740

45. Britschgi C, Jenal M, Rizzi M et al (2008) HIC1 tumour suppressor gene is suppressed in acute myeloid leukaemia and induced during granulocytic differentiation. $\mathrm{Br} \mathrm{J}$ Haematol 141:179-187

46. Chen W, Cooper TK, Zahnow CA et al (2004) Epigenetic and genetic loss of Hic1 function accentuates the role of p53 in tumorigenesis. Cancer Cell 6:387-398

47. Stokke T, DeAngelis P, Smedshammer L et al (2001) Loss of chromosome 11q21-23.1 and 17p and gain of chromosome $6 \mathrm{p}$ are independent prognostic indicators in B-cell non-Hodgkin's lymphoma. Br J Cancer 85:1900-1913

48. Milner J, Medcalf EA (1991) Cotranslation of activated mutant p53 with wild type drives the wild-type p53 protein into the mutant conformation. Cell 65:765-774 